\title{
AS\&T:
}

\section{Impacto da pandemia por covid-19 no brasil}

\author{
Antonio Marcos Rodrigues Pereira ${ }^{1,2}$; Daniel Ramos da Costa ${ }^{1}$; Camila Fernandes da Costa ${ }^{1}$; Letícia \\ Bonfim Campos'; Isabella Brum de Mattos Magalhães'; Paula Coimbra Garcia Teixeira'; Isabela Cristina \\ da Camara'; Valdemir Custodio de Vargas Junior'; Eidy de Oliveira Santos ${ }^{1}$.
}

\section{AUTHOR AFILIATIONS}

1 - Fundação Centro Universitário Estadual da Zona Oeste (UEZO), Rio de Janeiro.

2 - Instituto Oswaldo Cruz (Fiocruz), Rio de Janeiro.

\section{CONTACT}

eidyos@gmail.com

\section{ABSTRACT}

The COVID-19 pandemic has advanced in Brazilian territory, since the detection of the first case, in February 2020. The country came to lead the number of daily deaths, with more than 76 thousand deaths in July 2020. The Southeast region has become the highest in number of deaths in the country, led by São Paulo and Rio de Janeiro. Quarantine and social isolation were protocols adopted to contain the spread of the pandemic and prevent a collapse in the health system. However, this context has caused damage to the mental health of part of the population, and disorders such as anxiety, depression, sleep problems, stress, as well as domestic violence and divorce have increased throughout the pandemic period. During the pandemic, the poorest social classes were more exposed to the risk of contracting COVID-19, this due to their work in the informal market, as well as the lack of minimum hygiene conditions. Previous studies about COVID-19 transmission by animals suggested that cats and ferrets can transmit the disease only to the same species animals, however, the unique that has been involved in transmission to humans was the mink. Aiming to contain the advance of COVID-19, the scientific world has developed different vaccines and many countries have already started their vaccination programs. However, compared to other countries, Brazil is still late with vaccination coverage. Although the vaccination program has already started, many people still do not intend to be vaccinated, which makes it difficult to achieve vaccination coverage and contain the spread of the pandemic.

Keywords: Coronavirus, COVID-19 pandemic, social isolation, vaccination, animal transmission.

\section{RESUMO}

A pandemia por COVID-19 avançou no território brasileiro, desde a detecção do primeiro caso, em fevereiro de 2020 . O país chegou a liderar o número de mortes diárias, com mais de 76 mil mortes em julho de 2020. A região Sudeste se tornou o território com maior número de mortes no País, liderados por São Paulo e Rio de Janeiro. A quarentena e o isolamento social foram medidas adotadas com intuito de conter a disseminação da pandemia e evitar um colapso no sistema de 
saúde. Porém, este contexto tem acarretado danos à saúde mental de parte da população, e transtornos como ansiedade, depressão, problemas no sono, estresse, assim como, violência domiciliar e divórcios tem aumentado ao longo do período pandêmico. Durante a pandemia, as classes sociais mais pobres foram mais expostas ao risco de contrair a COVID-19, isso por conta da atuação no mercado informal, assim como, a ausência de condições mínimas de higiene. Estudos sobre a participação de animais na transmissão da COVID-19 sugerem que gatos e furões são capazes de transmitir a doença somente para animais da mesma espécie, no entanto, o único animal já descrito como transmissor para humanos foram os visons. A fim de conter o avanço da COVID-19, o mundo científico tem desenvolvido diferentes vacinas e muitos países já iniciaram seus programas de vacinação. No entanto, comparado com outros países, o Brasil ainda está atrasado com a cobertura de vacinação. Apesar do programa de vacinação já ter iniciado, muitas pessoas ainda não pretendem se vacinar, o que dificulta alcançar a cobertura vacinal e conter o avanço da pandemia.

Palavras-chave: Coronavírus, COVID-19, pandemia, isolamento social, vacinação, transmissão por animais.

\section{INTRODUÇÃO}

\section{Início estabelecimento da pandemia de}

\section{COVID-19}

Em dezembro de 2019 algumas pessoas que haviam visitado o mercado de frutos do mar de Huanan na cidade de Wuhan, província de Hubei, China, foram hospitalizadas com pneumonia, apresentando sintomas como tosse, febre e desconforto no peito (ZHU et al., 2020). Os médicos observaram que a doença era causada por um patógeno desconhecido e, com o intuito de identificar o patógeno, uma investigação epidemiológica e etiológica foi realizada pelas autoridades do Centro de Controle de Doenças da China (CDC) com amostras dos fluidos de lavagem bronco alveolar dos pacientes. Através de ensaios de PCR (RT-PCR), os pesquisadores identificaram a presença de um material genético com $85 \%$ similaridade de sequências com o Cononavírus causador da Síndrome Respiratória Aguda Grave de morcego (SARS-CoV) (ZHU et al. 2020). Assim, foi identificado que a doença era causada por um novo Coronavírus (SARS-CoV- 
2), cuja doença foi oficialmente nomeada COVID-19 (LI et al., 2020).

Os casos de COVID-19 na China aumentaram rapidamente, e em pouco tempo a doença foi capaz de alcançar 72 países, causando mais de 2.900 mortes, levando a Organização Mundial da Saúde (OMS) a declarar Emergência de Saúde Pública de Interesse Internacional (LI et al.,2020). A quantidade de indivíduos acometidos pela doença alcançou projeções alarmantes. Para conter o avanço da doença, uma série de medidas foram sendo implementadas em diversos países, como proibição de atividades com aglomeração, restrição de viagens, fechamento de escolas e universidades, assim como medidas distanciamento social e o incentivo pelo uso de máscaras faciais caseiras (AQUINO et al., 2020). No entanto, apesar das medidas adotadas, o nível de transmissão se manteve elevado e o contágio resultou em 118 mil casos em 114 diferentes países com mais de 4 mil óbitos, o que permitiu a OMS declarar pandemia causada pelo SARSCoV-2 no dia 11 de março (WHO 2020).

A transmissão da COVID-19 entre humanos ocorre através da interação de gotículas respiratórias contendo o vírus com a mucosa de indivíduos sadios (LI et al., 2020). Acredita-se que o vírus seja capaz de utilizar não só o trato respiratório como rota de infecção, como também o trato digestivo, o que poderia facilitar a propagação da doença, porém, novos estudos ainda são necessários para validar esta nova rota de transmissão (LI et al., 2020).

\section{Classificação e características dos}

\section{Coronavírus}

Os coronavírus pertencem à subfamília Orthocoronavirinae, da família Coronaviridae. Esta subfamília possui 4 gêneros, nomeados como Alphacoronavirus ( $\alpha-\mathrm{CoV})$, Betacoronavirus $(\beta-\mathrm{CoV})$, Gammacoronavirus $(\gamma-\mathrm{CoV})$ e Deltacoronavirus $(\delta-\mathrm{CoV})$. Destes gêneros já foi observado que os $\gamma-\mathrm{CoV}$ e $\delta-\mathrm{CoV}$ são capazes de infectar pássaros, sendo os $\alpha-\mathrm{CoV}$ e $\beta-\mathrm{CoV}$ descritos como eficientes em infectar mamíferos. No entanto, até 1960 seu potencial para causar infecções em humanos ainda não era conhecido (GÜNTHER et al., 2020).

Os vírus da família Coronaviridae são esféricos com aproximadamente $125 \mathrm{~nm}$, 
envelopados, apresentando um genoma de RNA com polaridade positiva e um tamanho aproximado de 30Kb. Uma característica marcante dos coronavírus são as projeções na superfície dos vírions que dão a eles a aparência de uma coroa quando olhado por microscopia eletrônica, o que inspira o nome (GÜNTHER et al., 2020; SOFI et al., 2020).

Os Coronavírus possuem algumas estruturais primárias essenciais, como: proteína de membrana (M), envelope (E) e nucleocapsídeo (N), e a proteína Spike (S) que apresenta um importante papel na ligação dos vírions a célula hospedeira (Figura 3). O domínio de ligação ao receptor $(\mathrm{RBD})$ presente na subunidade $\mathrm{S} 1 \mathrm{da}$ proteína Spike interage com a enzima conversora de angiotensina 2 (ACE2) na célula hospedeira promovendo a internalização do vírus, onde é capaz de replicar e gerar novos vírions (SOFI et al., 2020).

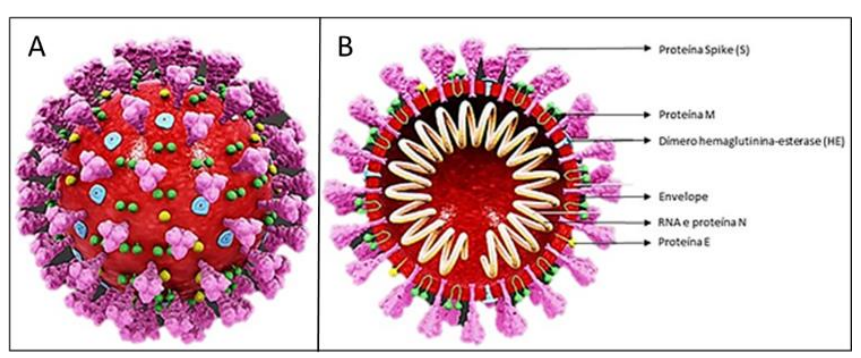

Figura 1: Estrutura tridimensional (3D) dos coronavírus. Adaptado de SOFI et al., 2020.

\section{A pandemia no Brasil e os principais}

\section{acontecimentos}

Muitos acontecimentos foram marcantes durante a pandemia de COVID-19 no Brasil, sendo o primeiro caso confirmado em 26 de fevereiro de 2020, alguns dias antes da OMS declarar a pandemia por um novo Coronavírus. O paciente tinha recentemente retornado da Itália, e em seguida alguns sintomas foram sendo manifestados (CAVALCANTE et al., 2020). Nos meses seguintes os números de casos foram ampliados de forma expressiva, alcançando mais de 7 milhões de casos até o fim de dezembro (Figura 2A), onde um total de 194.949 evoluíram ao óbito (Figura 2B) (Secretaria de saúde 2020).

Algumas regiões do Brasil foram mais impactadas pelo avanço da COVID-19. A região Sudeste possui os maiores índices de casos e óbitos decorrentes de COVID-19, e ao somar os óbitos de São Paulo e Rio de Janeiro é possível alcançar mais de 60 mil mortes decorrentes de COVID-19 somente no ano 2020 (Figura 2C). Apesar do número alarmante de óbitos envolvendo COVID-19, acredita-se que somente 
9,2\% dos casos envolvendo COVID-19 tenham

sido notificados no Brasil, o que permite acreditar que o número real de indivíduos infectados e mortos seja ainda maior (DO PRADO et al., 2020).

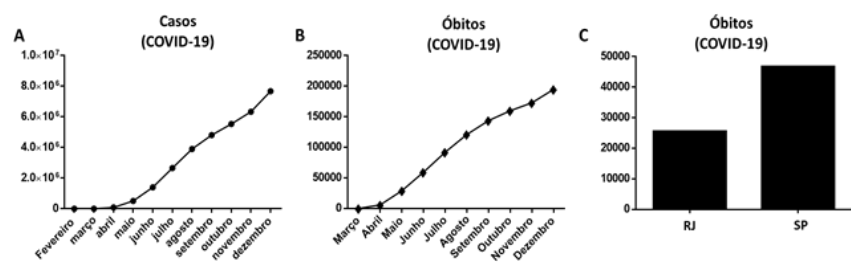

Figura 2: Número de casos e óbitos de COVID-19 no Brasil em 2020. (A) Número de casos de COVID-19 registrados no Brasil entre os meses de fevereiro e dezembro do ano de 2020. (B) Número de óbitos decorrentes de COVID-19 registrado no Brasil entre os meses de março e dezembro do ano de 2020. (C) Número de óbitos decorrentes de COVID-19 registrados no Rio de janeiro e São Paulo em 2020. Os dados foram recuperados da plataforma https://covid.saude.gov.br/.

O mês de março no Brasil foi marcado pelo início da pandemia, constatado pelo aparecimento de mais 8 casos confirmado e da primeira transmissão interna no país (Figura 3A). Como tentativa de conter o avanço da doença o Ministério da Saúde (MS) ampliou medidas de reforço da assistência hospitalar, iniciou a compra de testes rápidos de diagnóstico e regulamentou critérios de quarentena e isolamento social de pessoas com suspeita de casos ou confirmação sintomática da COVID-19. A partir da terceira semana de março, quando houve a primeira morte pela doença, o governo brasileiro decreta situação de emergência no país, suspende eventos e atividades coletivas, com exceção de atividades consideradas essenciais, para mitigar a transmissão comunitária de COVID-19, e começa a restringir o acesso de estrangeiros no País.

No mês seguinte a doença começa a alcançar estágios alarmantes e na terceira semana de abril todos os estados do Brasil já haviam registrados mortes decorrentes de COVID-19, liderados pelo Estado de São Paulo, com 15 mil casos. No início deste mês, o MS tornou a utilização de máscaras uma medida sanitária obrigatória e passou a incentivar potenciais alternativas de tratamento, como a cloroquina e a hidroxicloroquina associada ao antibiótico azitromicina. Em paralelo, a comunidade científica e médica, brasileira e mundial, realizam ensaios clínicos e testes com tais medicamentos, assim como a utilização de plasma sanguíneo de pacientes curados de COVID-19 para tratamento, sendo apenas última apresentando sucesso. De forma alarmante, muitos profissionais da saúde passaram a alertar sobre a falta de insumos no atendimento dos pacientes, o que resultou no 
registro de mais de 3 mil denúncias por faltas de equipamentos de proteção individual (EPIs). Neste período a pandemia avança de forma acelerada e muitas incertezas políticas começam a surgir, o que acarretou na troca consecutiva de dois Ministros da Saúde. Com a aprovação, pela Anvisa, do uso de testes rápidos para COVID-19 em farmácias, o final do mês de abril foi marcado por 67 mil casos da doença e mais de 4 mil mortes (Figura 3A).

No início de maio, já havia 8.536 mortes por COVID-19 e mais de 125 mil pessoas diagnosticadas com a doença. $\mathrm{O}$ avanço da pandemia resultou em muitas mortes e ao chegar no final do mês de maio o Brasil já registrava mais de mil mortes diárias. O estado de São Paulo somava mais óbitos que todo o território Chinês, com mais de 4.600 mortes. O MS passou então a divulgar protocolos para uso da cloroquina e hidroxicloroquina em casos leves de COVID, apesar dos resultados científicos serem inconclusivos sobre a eficácia destes tratamentos. Neste momento a OMS reconheceu o Brasil como o país sul-americano mais afetado pela pandemia e criticou o estímulo a ampliação do uso da cloroquina para esta doença (Figura 3A).

Após um período de restrição comercial, junho é um período marcado pela flexibilização de muitos serviços, no entanto, entidades de saúde enfatizam a necessidade de evitar qualquer exposição desnecessária. Neste período o Brasil recebeu o primeiro lote de vacinas contra COVID-19, desenvolvida pela Universidade de Oxford, Inglaterra, para a testagem em voluntários. Uma parceria entre o Brasil, a farmacêutica AstraZeneca e a universidade de Oxford fora anunciada informando sobre o desenvolvimento e produção da vacina com o uso da tecnologia dos laboratórios da Fundação Oswaldo Cruz (Fiocruz). Em paralelo, este período é marcado pela liderança do Brasil no número diário de mortes por Covid-19, sendo, infelizmente, responsável por uma em cada quatro mortes nas Américas, segundo a OMS (Figura 3A).

O segundo semestre de 2020 no Brasil é marcado pela alta taxa de óbitos decorrentes de COVID-19 e até julho era somado mais de 76 mil mortes. Após um longo período de testes, em 
novembro chegaram 120 mil doses da vacina

Coronavac produzida pela Sinovac em parceria com o instituto Butantan em São Paulo. No entanto, os dados já somavam mais de 150 mil vítimas fatais decorrentes de COVID-19 (Figura

3B).

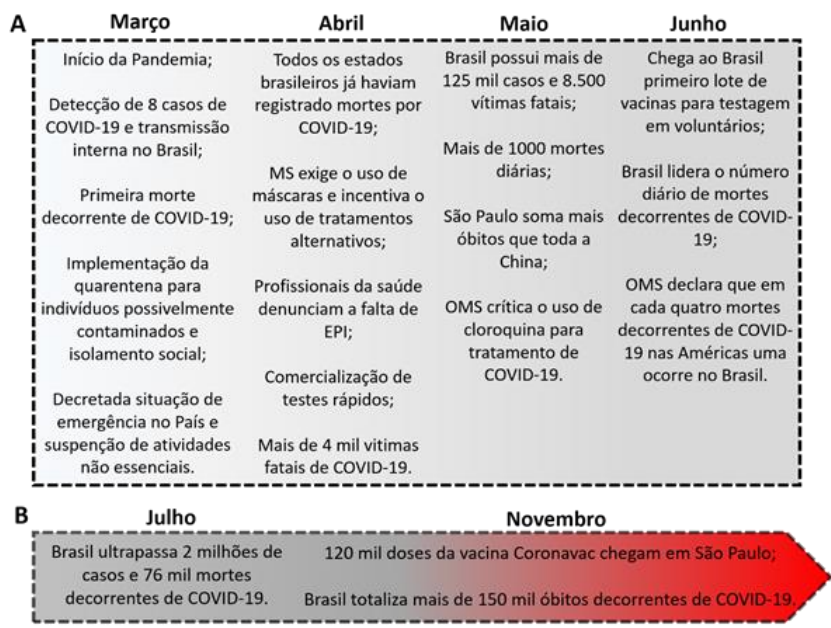

Figura 3. Linha do tempo com os principais eventos mundiais e brasileiros associados a pandemia de COVID-19. (A) Principais acontecimentos que marcaram o início da pandemia no Brasil durante o primeiro semestre de 2020. (B) Meses que evidenciaram o agravamento dos óbitos decorrentes de COVID-19 durante o segundo semestre de 2020 e a chegada dos imunizantes no Brasil. A mudança de tonalidade da esquerda para direita indica o acúmulo de óbitos decorrentes de COVID-19 no Brasil.

\section{Impacto social da pandemia de COVID-19 na}

\section{população brasileira}

O isolamento social tem sido uma postura apoiada pelas entidades de saúde como meio de conter a disseminação de COVID-19 e evitar um colapso no sistema de saúde do País (AQUINO et al., 2020). No entanto, o contexto pandêmico juntamente com o distanciamento social tem acarretado danos à saúde mental de parte da população, incluindo profissionais do sistema de saúde (RAMÍREZ-ORTIZ et al., 2020). O alcance dos efeitos negativos para a saúde mental, causados pela pandemia é normalmente maior que o alcance do vírus em si. Dessa forma, estima-se que um terço da população, possa sofrer alguma manifestação psicológica ou psiquiátrica, caso não haja nenhuma intervenção, visando a manutenção da saúde mental (LIMA, 2020; ORNELL et al., 2020).

Entre os problemas psíquicos e transtornos mentais mais comuns é possível citar o estresse, alterações do sono e do humor, assim como sentimento de frustação e o medo de contrair a COVID-19 (BARROS et al., 2020). Como é descrito na literatura, sabe-se que os transtornos mentais podem comprometer o sistema imunológico do indivíduo (VISMARI et al.,2008), podendo acarretar em fatores de riscos para doenças virais ou crônicas (COUGHLIN, 2012; DHAR \& BARTON., 2016). 
Alguns fatores estão sendo relacionados com o nível de estresse adquirido durante a pandemia, entre estes está a veiculação de informações falsas sem cunho científico, assim como o tempo de noticiário sobre a pandemia (BARROS et al., 2020). Como observado por Barros e colaboradores (2020) durante a pandemia o sentimento frequente de tristeza/depressão alcançou $40 \%$ dos adultos brasileiros, e dentro desta população estudada, a ansiedade/nervosismo foi uma característica reportada por mais de $50 \%$ destes indivíduos. Além disso, uma parcela de indivíduo composta por adultos jovens, mulheres e pessoas com diagnóstico prévio de depressão tiveram uma maior prevalência no índice de tristeza/ansiedade/problemas do sono (BARROS et al., 2020). Neste cenário, no qual há propensão ao aumento do estresse e desequilíbrio emocional, diversos problemas familiares vêm se tornando mais frequentes. Dentre estes, destacam-se o aumento da violência doméstica, bem como, da taxa de divórcios (BRADBURY et al., 2020; PETERMAN et al., 2020).
Dentro do convívio social entre os seres humanos, acredita-se que fatores como a capacidade de abstração, de comunicação e de convívio em sociedade tenham sido determinantes para o sucesso evolutivo da humanidade (HOPF et al., 2014). Se no passado, a interação social contribuiu para obtenção de alimento e proteção de seus grupos, atualmente, o ambiente social do indivíduo desempenha um papel significativo em seu bem-estar físico e mental. Estudos sugerem que a interação com pessoas queridas tem efeito direto sobre a melhora do humor, sensação de segurança e conforto, o que por sua vez, influencia positivamente o sistema imunológico (AVITSUR et al., 2009; MURRAY et al., 2020). Em contrapartida, pessoas que interagem pouco com outros, tendem a se sentir mais solitárias e a desenvolver distúrbios psicológicos com maior frequência, além de estarem mais susceptíveis a um sistema imune debilitado (AVITSUR et al., 2009; MURRAY et al., 2020).

Durante o período de pandemia, as classes sociais mais pobres têm sido mais expostas ao risco de contrair a COVID-19 (NATIVIDADE et 
al., 2020). Este efeito é potencializado pela desigualdade social entre a população brasileira, onde os indivíduos que atuam no mercado informal não conseguem aderir ao isolamento, pois a manutenção da sua atividade não os permite (NATIVIDADE et al., 2020). Além disso, as condições de vulnerabilidade presente nesta classe da população os restringe muitas vezes a falta de condições mínimas de higiene, assim como o acesso a informações de qualidade (BEZERRA et al., 2020; LEE, 2020; PIRES, 2020). Além do mais, estas famílias são incapazes de isolar qualquer caso familiar de COVID-19, pois parte desta população compartilham de poucos cômodos domésticos em suas residências (BEZERRA et al., 2020; LEE, 2020; ÖLCER et al., 2020). Como consequência destas circunstâncias, os indivíduos de baixa renda acabam tendo sua saúde física e mental mais fragilizadas em tempos de pandemia de COVID19 (BEZERRA et al., 2020; ÖLCER et al.,2020). Com o avanço da COVID-19 muito foi discutido sobre a participação dos animais na transmissão da doença aos seres humanos e/ou outros animais. Poucos estudos ainda foram feitos para esclarecer o real envolvimento dos animais neste cenário, porém, países como Bélgica, França, Holanda, Alemanha ,Rússia , Dinamarca ,Estados Unidos, e China já citaram casos de animais contaminados (KIROS et al., 2020; ORESHKOVA et al., 2020).

Muitos casos de COVID-19 têm sido reportados em diferentes animais, como: macaco, cão guaxinim, visom, leão e tigre (KIROS et al., 2020). Apesar de pouco se saber sobre a participação dos animais na transmissão da COVID-19, atualmente tem sido esclarecido que os furões e gatos são animais altamente susceptíveis ao SARS-CoV-2, sendo capazes de transmitir a doença através de gotículas respiratórias aos animais da mesma espécie (SHI et al., 2020). Neste mesmo estudo o autor descreve que os cães são animais que apresentam baixa susceptibilidade ao SARS-CoV-2; sendo os porcos, patos e galinhas animais que não possuem susceptibilidade ao patógeno (SHI et al., 2020). Embora ainda não se saiba sobre a participação destes animais na rota de transmissão da COVID19, acredita-se que os visons sejam animais 
capazes de transmitir a doença ao Homem (ORESHKOVA et al., 2020).

Dentro dos avanços científicos necessários para entender os efeitos causados pelo SARS-CoV-2, assim como a eficácia de potencias alvos terapêuticos, diferentes modelos animais têm sido estudados (CLEARY et al., 2020). Como mencionado anteriormente, o vírus utiliza a enzima ACE2 da célula hospedeira como mecanismo para invadir as células (SOFI et al., 2020). Com isso, os animais que possuem alta similaridade proteica com o receptor ACE2 humano têm sido utilizados como modelo de estudo de COVID-19 (CLEARY et al., 2020). Por apresentarem características necessárias para a replicação e disseminação viral, atualmente sabese que animais como o hamster-sírio (CHAN et al., 2019), macaco verde africano (CROSS et al., 2020) macaco rhesus (YU et al., 2020) e furão (CLEARY et al., 2020) são potenciais modelos animais para os estudos sobre COVID-19.

\section{A vacina contra COVID-19 no contexto brasileiro}

Ao decorrer da história humana, a vacinação foi responsável pelo controle de diversas doenças, como varíola, febre amarela, poliomielite, sarampo, caxumba e rubéola (HINMAN, 1999; MULLER et al., 2007; SCHATZMAYR et al., 2002). Em algumas regiões foi possível chegar até o estágio de erradicação (MULLER et al., 2007; SCHATZMAYR et al., 2002). Por conta disso, a vacinação é considerada um dos métodos mais eficazes contra morbidade e mortalidade causadas por doenças endêmicas e emergentes (IWASAKI \& OMER, 2020).

Durante o período de pandemia o cenário mundial enfatizava a necessidade da vacina contra COVID-19 como uma possível solução para o expressivo número de mortes causadas pela doença (TREGONING et al., 2020). Deste modo, muitas pesquisas foram impulsionadas de forma conjunta para o mesmo objetivo, e como resultado, muitas vacinas candidatas foram sendo desenvolvidas ao mesmo tempo (RAJA et al., 2020).

Durante o desenvolvimento de uma nova vacina são necessárias diversas etapas para 
garantir a eficácia e a segurança do imunizante.

Para isso são realizados diferentes estudos

categorizados em fase exploratória, fase préclínica e clínica (KHUROO et al., 2020). Durante a fase exploratória são realizados ensaios laboratoriais de pesquisa básica a fim de identificar antígenos sintéticos ou naturais candidatos ao desenvolvimento da vacina (KHUROO et al., 2020). A fase pré-clínica é formada por etapas com testes em cultura de células e modelos animais que analisam características imunogênicas, toxicidade, assim como as doses iniciais para testes em humanos (KHUROO et al., 2020). Os estudos realizados durante a fase clínica são divididos em diferentes etapas (Fase I, Fase II e Fase III e Fase IV) e dão início aos testes em humanos. Para iniciar a Fase I são recrutados entre 20-100 voluntários sadios no qual serão submetidos a testes para investigar a resposta imune frente ao estímulo com vacina candidata, assim como os efeitos sobre a saúde (KHUROO et al., 2020). A Fase II tem como objetivo identificar a dose ideal garantindo a saúde do indivíduo, bem como a via de administração do imunizante e o intervalo entre as doses (KHUROO et al. 2020 ;SINGH \& MEHTA, 2016). Nesta fase o grupo teste é ampliado e são recrutados centenas de voluntários com características semelhantes do público-alvo, assim como grupos de ambos os sexos, de diferentes idades e etnias (KHUROO et al. 2020 ;SINGH \& MEHTA, 2016). Por fim, a Fase III é constituída por um estudo em larga escala realizado com milhares de voluntários da população-alvo com o objetivo de avaliar melhor a eficácia e a segurança da vacina candidata antes de sua disponibilização do produto (SINGH \& MEHTA, 2016). E para alcançar os valores de eficácia da vacina são analisados de forma percentual a redução na incidência da doença ou da infecção entre os voluntários vacinados (SINGH \& MEHTA, 2016). A Fase IV , também conhecida como fase pós comercialização, ocorre após o licenciamento e a distribuição do produto. Nesta fase é feito um acompanhamento dos efeitos adversos causados pela vacina após o processo de comercialização do imunizante (SINGH \& MEHTA, 2016).

Atualmente diversas vacinas candidatas contra COVID-19 estão em fase de teste (KAUR 
\& GUPTA, 2020), porém alguns imunizantes já foram autorizados e estão sendo disponibilizados mundialmente para auxiliar no controle da pandemia (BURKI, 2020). As vacinas comercializadas atualmente apresentaram uma eficácia superior aos $50 \%$ exigidos pela OMS. Além destas informações, dados como o fabricante e a tecnologia utilizada para a produção das vacinas podem ser analisados na tabela abaixo (Tabela 1).

Tabela 1: Vacinas disponibilizadas contra COVID-19.

\begin{tabular}{|c|c|c|c|c|}
\hline $\begin{array}{c}\text { Nome da } \\
\text { vacina }\end{array}$ & Desenvolvedor & Tecnologia & Eficácia & Referências \\
\hline Coronavac & Sinovac & $\begin{array}{l}\text { SARS-CoV } \\
\text { inativado }\end{array}$ & $\begin{array}{c}\text { superior } \\
\text { a } 50 \%\end{array}$ & $\begin{array}{c}\text { Palacios et al } \\
\text {., } 2020\end{array}$ \\
\hline Ad26.COV2.S & Johnson \& Johnson & Vetor viral & $66 \%$ & $\begin{array}{c}\text { Johnson \& } \\
\text { Johnson ., } \\
2021\end{array}$ \\
\hline BNT162b2 & BioNTech/Pfizer & RNam & $95 \%$ & \multirow{4}{*}{ Burki ., 2020} \\
\hline AZD12222 & Oxford/AstraZeneca & Vetor viral & $90 \%$ & \\
\hline mRNA-1273 & Moderna & RNam & $94,5 \%$ & \\
\hline Sputnik V & Gamaleya & Vetor viral & $92 \%$ & \\
\hline
\end{tabular}

avança e atinge $67 \%$ da população é alcançado a imunidade de rebanho. Este feito confere imunidade indireta contra a infecção e permite que indivíduos susceptíveis se tornem protegidos contra a doença (RANDOLPH \& BARREIRO., 2020). Apesar de muitos países terem avançado com a campanha de vacinação, ainda pouco foi alcançado no Brasil. O atual plano de vacinação do Brasil é divido em 4 fases e a primeira fase ainda não foi concluída. Como alvo da primeira fase de vacinação estão os trabalhadores da saúde, assim como os idosos a partir dos 75 anos de idade, as pessoas com 60 anos ou mais que vivem em instituições de longa permanência (asilos e instituições psiquiátricas) e a população indígena. Na segunda fase, entram pessoas de 60 a 74 anos. A terceira fase prevê a imunização de pessoas com comorbidades que apresentam maior chance para agravamento da doença (como portadores de doenças renais crônicas, cardiovasculares, entre outras). A quarta e última fase deve abranger professores, forças de segurança e salvamento, funcionários do sistema prisional e população privada de liberdade (Ministério da Saúde, 2020). O Brasil começo seu programa de vacinação com um ritmo bastante lento, alcançando $4,13 \%$ da população vacinada com a primeira dose e $1,41 \%$ com a segunda dose, no final de 2020. Em 2021, a velocidade de vacinação foi apenas expressiva a partir de maio. Atualmente (em 28 de junho de 2021), a cobertura vacinal estava em 71.369.215 vacinados com a $1^{\mathrm{a}}$ dose $(33,7 \%$ da população 
brasileira), sendo que 25.344 .765 pessoas

também foram vacinadas com a $2^{\mathrm{a}}$ dose $(12,09 \%$

da população), segundo o consórcio de veículos

de imprensa a partir de dados das secretarias

estaduais

de

Saúde

(https://especiais.g1.globo.com/bemestar/vacina/

2021/mapa-brasil-vacina-covid/).

Apesar da necessidade imediata de um

amplo alcance no processo de vacinação contra COVID-19, ainda muitos grupos antivacinas se manifestam contra a medida (HOTEZ.,2020). Em uma pesquisa de opinião nos Estados Unidos, somente metade dos estadunidenses demostraram interesse em se vacinar contra a COVID-19, em contrapartida, uma parcela de $25 \%$ de cidadãos apresentaram incertezas sobre a vacinação (GUIMARÃES, 2020). Uma pesquisa semelhante foi realizada no Brasil durante dezembro de 2020 e curiosamente foi identificado que o número de pessoas que não pretendiam se vacinar aumentou. Nesta pesquisa foi identificado que $22 \%$ dos entrevistados não eram favoráveis à vacinação, enquanto em agosto o número era de 9\%. De forma simultânea foi registrada uma queda no número de indivíduos que pretendiam se vacinar, em agosto os números registraram $89 \%$ e em dezembro $73 \%$ (FOLHA DE S. PAULO. 2020)

\section{REFERÊNCIAS}

AQUINO, E. M. L. et al. Social distancing measures to control the COVID-19 pandemic: Potential impacts and challenges in Brazil. Ciencia e Saude Coletiva, v. 25, p. 2423-2446, 2020.

AVITSUR, R. et al. Social Interactions, Stress, and Immunity. Immunology and Allergy Clinics of North America, v. 29, n. 2, p. 285293, 2009.

BARROS, M. B. DE A. et al. Relato de tristeza/depressão, nervosismo/ansiedade e problemas de sono na população adulta brasileira durante a pandemia de COVID-19. Epidemiologia e servicos de saude : revista do Sistema Unico de Saude do Brasil, v. 29, n. 4, p. e2020427, 2020.

BEZERRA, A. C. V. et al. Factors associated with people's behavior in social isolation during the covid-19 pandemic. Ciencia e Saude Coletiva, v. 25, p. 2411-2421, 2020.

BRADBURY-JONES， C.; ISHAM， L. The pandemic paradox: The consequences of COVID-19 on domestic violence. Journal of Clinical Nursing, v. 29, n. 13-14, p. 2047-2049, 2020.

BURKI, T. "Equitable distribution of COVID-19 vaccines". The Lancet Infectious Diseases, ISSN: 1473-3099, Vol: 21, Issue: 1, Page: 33-34

CAVALCANTE, J. R. et al. COVID-19 no Brasil: evolução da epidemia até a semana epidemiológica 20 de 2020. Epidemiologia e 
servicos de saude : revista do Sistema Unico de Saude do Brasil, v. 29, n. 4, p. e2020376, 2020.

CHAN, J. F. et al. Title: Simulation of the clinical and pathological manifestations of Coronavirus Disease 2019 (COVID-19) in golden Syrian hamster model: implications for disease pathogenesis and transmissibility Authors: Jasper Fuk-Woo Chan. Clin Infect Dis., v. 2019, p. 150, 2019.

CLEARY, S. J. et al. Animal models of mechanisms of SARS-CoV-2 infection and COVID-19 pathology. British Journal of Pharmacology, v. 177, n. 21, p. 4851-4865, 2020.

COUGHLIN, S. S. Anxiety and depression: linkages with viral diseases. Public Health Reviews, v. 34, n. 2, p. 1-17, 2012.

Cresce parcela que não quer se vacinar contra Covid-19, e maioria descarta imunizante da China. Folha de S.Paulo, São Paulo, 12.dez.2020. Disponível em: <https://www1.folha.uol.com.br/equilibrioes aude/2020/12/cresce-parcela-que-nao-quer-sevacinar-contra-covid-19-e-maioria-descartaimunizante-da-china.shtml>. Acesso em: 09 de mar.de 2021.

CROSS, R. W. et al. Intranasal exposure of African green monkeys to SARS-CoV-2 results in acute phase pneumonia with shedding and lung injury still present in the early convalescence phase. Virology Journal, v. 17, n. 1, p. 1-12, 2020.

DHAR, A. K.; BARTON, D. A. Depression and the link with cardiovascular disease. Frontiers in Psychiatry, v. 7, n. MAR, p. 1, 2016.

DO PRADO, M. F. et al. Analysis of COVID-19 under-reporting in Brazil. Revista Brasileira de Terapia Intensiva, v. 32, n. 2, p. 224-228, 2020.

GUIMARÃES, R. Anti-covid vaccines: A look from the collective health. Ciencia e Saude Coletiva, v. 25, n. 9, p. 3579-3585, 2020.
HAN, S. Clinical vaccine development. Clin Exp Vaccine Res., v. 4, n. (1), p. 46-53, 2015.

HINMAN, A. VACCINE-PREVENTABLE DISEASES. Annu. Rev. Public Health, v. 20, p. 211-29, 1999.

HOPF, T. A. et al. Sequence co-evolution gives $3 \mathrm{D}$ contacts and structures of protein complexes. eLife, v. 3, p. 1-45, 2014.

HOTEZ PJ. COVID19 meets the antivaccine movement. Microbes Infect., v. 22, n. 4-5, p. 162-164, 2020.

IWASAKI, A.; OMER, S. B. Why and How Vaccines Work. Cell, v. 183, n. 2, p. 290-295, 2020.

JUSTIZ VAILLANT AA, GRELLA MJ. Vaccine (Vaccination) [Updated 2021 Feb 16]. In: StatPearls [Internet]. Treasure Island (FL): StatPearls Publishing; 2021 Jan-. Available from:

https://www.ncbi.nlm.nih.gov/books/NBK53289 $\underline{5 /}$

Johnson \& Johnson Announces Single-Shot Janssen COVID-19 Vaccine Candidate Met Primary Endpoints in Interim Analysis of its Phase 3 ENSEMBLE Trial. JNJ. Disponível em <https://www.jnj.com/johnson-johnsonannounces-single-shot-janssen-covid-19vaccine-candidate-met-primary-endpoints-ininterim-analysis-of-its-phase-3-ensemble-trial> . Acesso em 28/02/2021

KAUR, S. P.; GUPTA, V. COVID-19 Vaccine : A comprehensive status report. Virus Res., v. 288, 2020.

KHUROO, M. S. et al. COVID-19 Vaccines: A Race Against Time in the Middle of Death and Devastation! Journal of Clinical and Experimental Hepatology, v. 10, n. 6, p. 610621, 2020. 
KIROS, M. et al. COVID-19 pandemic: Current knowledge about the role of pets and other animals in disease transmission. Virology Journal, v. 17, n. 1, p. 1-8, 2020.

LEE, Y. Since January 2020 Elsevier has created a COVID-19 resource centre with free information in English and Mandarin on the novel coronavirus COVID-. Ann Oncol, n. January, p. 19-21, 2020.

LI, H. et al. Coronavirus disease 2019 (COVID19) in Zhejiang, China: an observational cohort study. International Journal of Antimicrobial Agents, v. 55, n. 5, p. 105951, 2020.

LIMA, R. C. Distanciamento e isolamento sociais pela COVID-19 no Brasil: Impactos na saúde mental. Physis, v. 30, n. 2, p. 1-10, 2020.

Mapa da vacinação contra Covid-19 no Brasil. G1, São Paulo, 09 de mar. de 2021. Disponível em

$<$ https://especiais.g1.globo.com/bemestar/vacina /2021/mapa-brasil-vacina-covid/> . Acesso em 09 de mar. de 2021

MULLER, C. P. et al. Reducing global disease burden of measles and rubella: Report of the WHO Steering Committee on research related to measles and rubella vaccines and vaccination, 2005. Vaccine, v. 25, n. 1, p. 1-9, 2007.

MURRAY DR, HASELTON MG, FALES M, COLE SW. Falling in love is associated with immune system gene regulation. Psychoneuroendocrinology.

2019;100:120-126.

doi:10.1016/j.psyneuen.2018.09.043

NATIVIDADE, M. DOS S. et al. Social distancing and living conditions in the pandemic COVID-19 in Salvador-Bahia, Brazil. Ciencia e Saude Coletiva, v. 25, n. 9, p. 3385-3392, 2020.

ÖLCER, S., YILMAZ-ASLAN, Y. \& BRZOSKA, P. Lay perspectives on social distancing and other official recommendations and regulations in the time of COVID-19: a qualitative study of social media posts. BMC Public Health 20, 963 (2020).

ORESHKOVA, N. et al. SARS-CoV-2 infection in farmed minks, the Netherlands, April and May 2020. Eurosurveillance, v. 25, n. 23, p. 1-7, 2020 .

ORNELL, F. et al. "Pandemic fear" and COVID-19: Mental health burden and strategies. Brazilian Journal of Psychiatry, v. 42, n. 3, p. 232-235, 2020.

PALACIOS R. et al. Double-Blind, Randomized, Placebo-Controlled Phase III Clinical Trial to Evaluate the Efficacy and Safety of treating Healthcare Professionals with the Adsorbed COVID-19 (Inactivated) Vaccine Manufactured by Sinovac - PROFISCOV: A structured summary of a study protocol for a randomised controlled trial. Trials. 2020 Oct 15;21(1):853.

Plano Nacional De Operacionalização Da Vacinação Contra A Covid-19. $1^{\circ}$ Edição. Ministério da Saúde, Brasília, 16/12/2020. Disponível em < https://www.gov.br/saude/ptbr/media/pdf/2020/dezembro/16/plano_vacinaca o_versao_eletronica.pdf $>$. Acesso em: 22/02/2021.

PETERMAN, A. et al. COVID-19, Family Stress and Domestic Violence: Remote Work, Isolation and Bargaining Power. Center for Global Development, n. 13570, p. 43, 2020.

PIRES, R. R. C. Os Efeitos sobre grupos sociais e territórios vulnerabilizados das medidas de enfrentamento à crise sanitária da Covid-19: propostas para o aperfeiçoamento da ação pública TT - Nota Técnica n. 33. Nota Técnica / IPEA Diest, v. 33, p. 11, 2020.

RAJA, A. A. T. A.; ALSHAMSAN, A.; ALJEDAI, A. Current COVID-19 vaccine candidates: Implications in the Saudi population. 
Saudi Pharmaceutical Journal, v. 28, n. 12, p. 1743-1748, 2020.

RAMÍREZ-ORTIZ, J. et al. Consecuencias De La Pandemia Covid 19 En La Salud Mental Asociadas Al Aislamiento Social. Revista Scielo Preprints, p. 21, 2020.

RANDOLPH, H.; BARREIRO LB. Herd immunity: Understanding Covid-19. Immunity, v. 52, n. 5, p. 737-741, 2020.

SCHATZMAYR, H. G. et al. Poliomielite no Brasil : a contribuição contribution of Fundação Oswaldo Cruz. História, Ciências, Saúde Manguinhos, v. 9, n. 1, p. 11-24, 2002.

SHI, J. et al. Susceptibility of ferrets, cats, dogs, and other domesticated animals to SARScoronavirus 2. Science, v. 368, n. 6494, p. 10161020, 2020.

SINGH, K.; MEHTA, S. The clinical development process for a novel preventive vaccine: An overview. J Postgrad Med., v. 62, n. (1), p. 4- 11., 2016.

SOFI, M. S.; HAMID, A.; BHAT, S. U. SARSCoV-2: A critical review of its history, pathogenesis, transmission, diagnosis and treatment. Biosafety and Health, v. 2, n. 4, p. 217-225, 2020.

TREGONING, J. S. et al. Vaccines for COVID19. Clinical and Experimental Immunology, v. 202, n. 2, p. 162-192, 2020.
UHTEG K, CARROLL KC, MOSTAFA HH. Coronavirus Detection in the Clinical Microbiology Laboratory: Are We Ready for Identifying and Diagnosing a Novel Virus?. Clin Lab Med. 2020;40(4):459-472. doi:10.1016/j.cll.2020.08.004

VISMARI, L.; JUSSILANE ALVES, G.; PALERMO-NETO, J. Revisão da Literatura Depressão, antidepressivos e sistema imune: um novo olhar sobre um velho problema Depression, antidepressants and immune system: a new look to an old problem. Revista Psiquiatria Clínica, v. 35, n. 5, p. 196-204, 2008.

World Health Organization (WHO). DirectorGeneral's opening remarks at the media briefing on COVID-19 - 11 March 2020. Disponível em < https://www.who.int/directorgeneral/speeches/detail/who-director-general-sopening-remarks-at-the-media-briefing-on-

covid-19---11-march-2020>. Acesso em: 22/02/2021.

YU, P. et al. Age-related rhesus macaque models of COVID-19. Animal Models and Experimental Medicine, v. 3, n. 1, p. 93-97, 2020.

ZHU, N. et al. A Novel Coronavirus from Patients with Pneumonia in China, 2019. New England Journal of Medicine, v. 382, n. 8, p. 727-733, 2020. 